\title{
GRANDES PROJETOS DE INVESTIMENTO: A CONSTRUÇÃo DE HIDRELÉTRICAS E A CRIAÇÃO DE NOVOS TERRITÓRIOS
}

\section{Great Projects of Investment: the Construction of Hydroelectric and the Creation of New Territories}

Carla Buiatti Cruz

Graduada em Geografia (Licenciatura) pela Universidade Federal de Uberlândia

Uberlândia/MG - Brasil

carlabuiatti_geo@yahoo.com.br

Vicente de Paulo da Silva

Prof. Dr. do IG/PPGEO da Universidade Federal de Uberlândia

Uberlândia/MG - Brasil

vicente@ig.ufu.br

Artigo recebido para publicação em 08/07/2009 e aceito para publicação em 01/03/2010

RESUMO: O presente artigo refere-se à parte teórica de uma pesquisa em andamento que busca estudar os efeitos da construção da Usina Hidrelétrica de Miranda no rio Araguari, bem como esses efeitos interferem na (re) organização do território. Para a compreensão do conceito de território, buscou-se como referência autores que têm dedicado atenção ao estudo desse tema tão importante para a Geografia. Além do território, foram destacados também os Grandes Projetos de Investimentos pela importância desses empreendimentos e pelo efeito que estes causam, quer seja para as pessoas, quer seja em nível do território. Assim, o intuito maior desse artigo é realizar uma discussão teórica acerca dos temas mencionados acima.

Palavras-chave: Grandes Projetos de Investimentos. Usina Hidrelétrica. Território.

ABSTRACT: This article shows the theoric part of a research which is being developed and study the effects of the Miranda's Hydroelectric construction, in Araguari river. It intends to show how much those effects change the (re)organization of a territory. The studies about territory obligate to have like references, different authors that have been dedicated attention to this theme, which is so important to Geography studies. Besides territory, it was gave attention to the term Great Project of Investments in function his importance and effects it cause to the people and to the territory. So, the mainly aim of this work is to realize a theoric discussion around those mentioned themes.

Keywords: Great Projects of Investments. Hydroelectric. Territory.

\section{INTRODUÇÃO}

A construção de uma usina hidrelétrica, dada sua abrangência, constitui o que pode ser chamado de Grandes Projetos de Investimentos, empreendimentos de grandes dimensões que 
Grandes Projetos de Investimento: a Construção de Hidrelétricas e a Criação de Novos Territórios Carla Buiatti Cruz, Vicente de Paulo da Silva

movimentam extraordinários montantes de dinheiro e outros recursos, tais como mão-de-obra e infraestrutura, além de uma grande disponibilidade de recursos naturais. A decisão pela sua implantação geralmente é favorecida pelo Estado, que tem papel decisivo na opção pela implantação de um Grande Projeto de Investimento.

No caso da Usina Hidrelétrica de Miranda, construída no rio Araguari, entre os municípios de Uberlândia - MG e Indianópolis - MG, essa decisão teve como base um planejamento energético elaborado para atender a demanda crescente de energia elétrica no estado de Minas Gerais.

A compreensão dos efeitos causados pela construção de uma obra desse porte exige que o pesquisador esteja munido de um referencial teórico capaz de contribuir com o entendimento das mais práticas questões, originadas de um grande projeto.

Neste sentido buscou-se, primeiramente, estudar os conceitos teóricos "grandes projetos" e "território", os quais constituem o principal objeto deste trabalho, por entender-se que é no território que os homens realizam suas ações e é nele que os efeitos dos grandes projetos podem ser observados de forma mais intensa e direta.

\section{GRANDESPROJETOSDE INVESTIMENTOS}

Os Grandes Projetos de Investimentos são considerados por Martins (1993, p.61) como "projetos econômicos de envergadura", os quais abrangem as hidrelétricas, os planos de colonização e construção de rodovias. Assim, os grandes projetos causam grandes e graves efeitos em relação ao meio e às pessoas, uma vez que no processo de implantação há "uma ausência de análises sobre as alterações socioeconômicas, culturais e ambientais que causariam às regiões" (BORTOLETO, 2001, p.54).

Os Grandes Projetos de Investimentos (GPIs) são aqueles que abarcam os empreendimentos de grande porte e surgiram sob o discurso de contribuir para a implantação de infra-estrutura e como forma de levar crescimento e progresso às regiões em que foram instalados. Assim, na definição de Bortoleto:

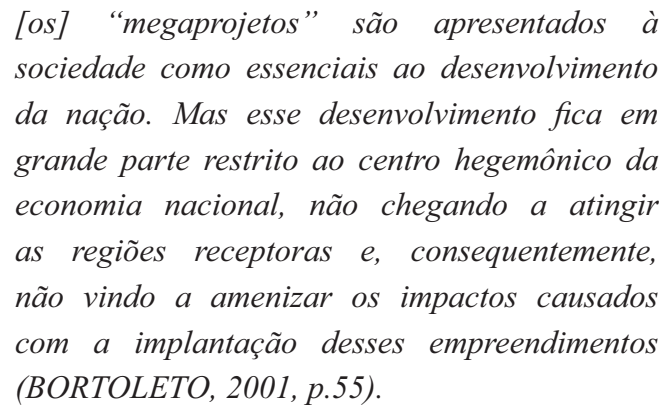

Diversos projetos dessa natureza foram inseridos no planejamento do país na década de 1970, quando as superintendências regionais perderam seu poder de atuação. Como forma de preencher essa lacuna deixada por elas, "houve a criação de um novo padrão de planejamento no País, o Grande Projeto de Investimentos (GPI), que surgiu ainda como gerador de novas regiões." (BORTOLETO, 2001, p. 54). Assim, o conceito começou a ser utilizado, quando "passaram a serem implantados no país projetos de investimentos que, por suas dimensões técnicas e financeiras, revelaram-se muito superiores aos empreendimentos até então existentes" (PIQUET apud BORTOLETO, 2001, p. 54).

De acordo com Vainer e Araújo (1992, p. 29), a definição da expressão Grandes Projetos de Investimento não é muito precisa, sendo usada para caracterizar aqueles projetos que movimentam "em grande intensidade elementos como capital, força de trabalho, recursos naturais, energia e território". Dito de outro modo, o GPI destaca-se pela grande mobilização de diferentes elementos que fazem parte deste projeto.

Tais elementos são movimentados a uma determinada região, no entanto esses projetos não contribuem para a diminuição das disparidades e desigualdades existentes entre as regiões do país. Ao contrário, as regiões onde estes projetos são implantados sofrem, de modo geral, com a "desestruturação das atividades econômicas 
preexistentes, o crescimento desordenado da população, desemprego, favelização, marginalização social, e, quase sempre, degradação ambiental" (VAINER e ARAÚJO, 1992, p. 33).

Os grandes projetos são "geradores de novas regiões” (VAINER E ARAÚJO, 1992, p. 31). São assim considerados porque atrai investimentos, necessitam mão-de-obra, mas também provocam deslocamentos para estas regiões. De um modo geral, esses grandes projetos acarretam certo "desenvolvimento", se pensarmos em termos puramente econômicos.

Assim, os grandes projetos podem ser caracterizados como modo de produção do espaço, uma vez que, conforme Vainer e Araújo (1992, p. 34 ), eles concretizam o processo de apropriação tanto de recursos naturais quanto humanos, em distintos pontos do território, obedecendo a uma lógica estritamente econômica.

Assim, as transformações no território causadas pelos grandes projetos são muitas,

Neste processo de mudança, além de alterações patrimoniais (novos proprietários) emorfológicas (nova geomorfologia, novo regime hidrico, etc.), instauram-se novas dinâmicas socioeconômicas, novos grupos sociais emergem na região de implantação, novos interesses e problemas se manifestam. (VAINER, 2008, p. 44-45).

Sendo que os GPIs modificam o território em que estão inseridos, no caso da Usina Hidrelétrica de Miranda, o território modificado para a construção da barragem e inundação de uma grande área é o território do rio. Entretanto, cabe dizer que nesse território existiam pessoas que desenvolviam atividades naquelas terras e de repente viram-se obrigadas a dispor das suas terras para que fosse construída a usina. Essa realidade de deslocamentos causados por Grandes Projetos de Investimentos é muito comum no nosso país, uma vez que existe no Brasil uma clara opção pela energia elétrica.
$\mathrm{Na}$ literatura acadêmica existem conceitos que se referem a essa população que é afetada por empreendimentos hidrelétricos. $\mathrm{O}$ conceito de atingido não representa apenas as dimensões econômicas e financeiras. Refere-se à legitimidade da propriedade e a detenção de direitos e possuem duas concepções: a concepção territorial-patrimonialista e a concepção hídrica.

A primeira refere-se a uma visão que não reconhece os impactos e nem o direito dos atingidos, mas "o que há é o direito de desapropriação por utilidade pública exercido pelo empreendedor" (VAINER, 2008, p. 42, grifo do autor). Essa concepção considera apenas os proprietários e descarta todos aqueles que apesar de não possuir título de posse necessitam da terra para sobreviver. Nessa concepção a área atingida restringe-se exclusivamente a área a ser inundada e a população atingida são os proprietários de terra nesse local, sendo esses proprietários considerados como um obstáculo à construção do empreendimento, e que necessitam ser removidos.

A segunda concepção identifica os atingidos e os inundados. Entretanto, mesmo identificando os não-proprietários, restringe os efeitos da construção do empreendimento à área que será inundada, e o atingido é entendido como inundado e, também, como deslocado compulsório devido à construção do empreendimento elétrico.

O conceito mais abrangente de atingido é o utilizado por agências multilaterais, principalmente pela incorporação do conceito de pessoas economicamente deslocadas, que são aquelas que têm suas atividades econômicas interrompidas. Dessa forma, para Vainer, "parece consensual entre as agências multilaterais que a noção de atingido remete ao conjunto de processos econômicos e sociais deflagrados pelo empreendimento que possam vir a ter efeitos perversos sobre os meios de vida da população." (2008, p. 50, grifo nosso).

Assim, o atingido é aquele que sofre os efeitos, seja eles econômicos ou simbólicos, e tem 
Grandes Projetos de Investimento: a Construção de Hidrelétricas e a Criação de Novos Territórios Carla Buiatti Cruz, Vicente de Paulo da Silva

o seu modo de vida modificado em decorrência da implantação de um projeto hidrelétrico, seja antes, durante ou depois da construção da usina.

\section{[...] No caso de comunidades dependentes da terra e de recursos naturais, [...] resulta na perda do acesso aos meios tradicionais de vida, incluindo a agricultura, a pesca, a pecuária, extração vegetal, para falar de alguns. Isso provoca não apenas rupturas na economia local como efetivamente desloca as populações - em um sentido mais amplo - do acesso a recursos naturais e ambientais essenciais ao seu modo de vida. Essa forma de deslocamento priva as pessoas de seus meios de produção e as desloca de seus modos de vida. Assim, o termo atingido, refere-se às populações que enfrentam um ou outro tipo de deslocamento (WORLD COMMISSION ON DAMS, apud VAINER, 2008, p. 51, grifo do autor).}

Percebe-se, então, que os efeitos negativos sobre essas populações são muitos, e em alguns casos esses efeitos são minimizados em função de determinadas alternativas. Entretanto, é importante destacar que esses efeitos não ocorrem apenas no momento da construção, ele é sentido no tempo e no espaço e às vezes podem causar problemas que irão seguir os atingidos durante anos. Além disso, tratase de pessoas que tem memórias e anseios, mas que por vezes são tratadas como coisas e não tem os seus sentimentos respeitados.

Não se pretende aqui questionar a necessidade e importância da energia elétrica para o desenvolvimento econômico do país. Mas há que se destacar que existem dois lados e, em muitos casos, o que acontece é que os envolvidos nesse processo destacam apenas o lado do progresso, e colocam a questão mais simples do que ela realmente é, uma vez que acham que pagando a indenização recompensam todos os transtornos e todas as perdas, inclusive afetivas, que os atingidos venham a sofrer. Assim, ocorre o deslocamento compulsório e o efeito nas populações é incalculável, uma vez que, existem coisas que não podem ser reconstruídas ou recompostas em outro local, e não há nada que recompense as perdas de lembranças que os atingidos sofrerão.

Há perdas que são resultantes da própria desestruturação de relações prevalecentes, da eliminação de práticas, da perda de valores e recursos imateriais (religiosos, culturais), por exemplo, a dispersão de um grupo familiar extenso, ou a inundação de lugares com importância simbólica, religiosa, para um determinado grupo social. (VAINER, 2008, p. 45).

Assim, anteriormente à construção da Usina Hidrelétrica de Miranda o homem tinha uma relação com a terra, desenvolvendo ali suas atividades. A partir da construção da usina houve uma ruptura nas relações sociais e econômicas dos proprietários atingidos, e os efeitos da implantação desse empreendimento precisam ser estudados. O território passa a ganhar novos usos e novos significados. Os modos de vida são transformados, os projetos de vida daquelas pessoas são destruídos e os laços afetivos que ligam o homem a terra são arrancados, de forma que ele não consegue impedir, e ele não tem outra opção a não ser se conformar com a sua nova situação e sofrer as consequências da expulsão daquela terra que nem sempre são favoráveis a ele.

\section{A OPÇÃO PELAS HIDRELÉTRICAS}

Cada vez mais usinas hidrelétricas são construídas no país, e cada vez mais o potencial hídrico é usado para geração de energia elétrica, sendo esta considerada por alguns como sendo necessária e indispensável ao desenvolvimento do país.

As decisões que são tomadas referentes a este assunto dificilmente consideram as populações locais, uma vez que, defendem interesses nacionais e, às vezes, até internacionais. Utilizam-se do discurso do progresso e do desenvolvimento das regiões para justificar a construção de hidrelétricas e a retirada de pessoas.

Assim, as populações locais que desenvolvem 
suas atividades naquele território, que será atingido pela implantação da hidrelétrica, ficam fora do processo de decisão e vê os seus direitos e suas vontades serem descartadas.

As usinas hidrelétricas causam muitos efeitos ao meio ambiente, além de interferir direta e indiretamente na vida das pessoas, principalmente nas que residem na área que será alagada pelo reservatório da usina. Os efeitos, assim, são muitos e causam a mudança na organização do território, provocando, dessa forma, alterações que devem ser estudadas para que se possa compreender o processo de criação e/ou (re) criação de um novo território, a partir da destruição dos já existentes e que eram habitados pela população que foi removida.

A utilização da água pra geração de energia é amplamente utilizada há muito tempo. Em países como o Brasil, onde o potencial hídrico é alto, as usinas hidrelétricas aparecem como uma alternativa para a geração de energia. A utilização deste meio é defendida por muitos, destacando-se, inclusive, o seu custo. De acordo com Schilling e Canese (1991, p. 20) esta é a "energia mais barata, e sempre que racionalmente explorada, das menos atentatórias ao equilíbrio ecológico". Assim, argumentam ainda alguns que do ponto de vista do meio ambiente, "é a que oferece as melhores condições, além de ser também economicamente mais vantajosa" (FEIJÓ \& OLIVEIRA, p. 03).

A energia elétrica é importante para a realização de diversas atividades, bem como para o desenvolvimento de determinadas regiões e atividades. A sua intensa utilização se dá principalmente, por ser a única de caráter renovável. No Brasil, a importância dessa forma de energia é tanta que ela corresponde a 91,08\% da participação da eletricidade na produção total (RELATÓRIO ONS/2006).

Nesse sentido, a demanda por energia elétrica cresce de forma significativa, produzindo efeitos diretos nas pessoas e nos seus territórios. No que se refere às populações atingidas, o que se percebe é que esta é vista como empecilho a construção das barragens e hidrelétricas, sendo elas ignoradas e deixadas de lado no processo de decisão. Não se considera a percepção destas: pensa-se apenas no lucro, em se conseguir vantagens, enquanto que o social e o ecológico são deixados de lado.

Assim, nesse processo de implantação de grandes projetos, novos atores são inseridos no processo histórico, e é nesse momento que surge o conflito com o outro, o estranho, resultando na criação de novas relações sociais.

Posto esse quadro, a população atingida é obrigada a restabelecer as suas relações sociais. E não é apenas isso. É-lhes retirado o necessário a sobrevivência destes - "terras e territórios, meios e condições de existência material, social, cultural e política” (MARTINS, 1993, p. 63).

O que se percebe é que os agentes responsáveis pela construção de hidrelétricas, por exemplo, têm apelado para a expulsão de moradores da área em transformação, provocado o deslocamento das pessoas atingidas pela intervenção, implicando transtornos e, em alguns casos, em conflitos entre os partidários da construção e os moradores, bem como as outras pessoas que serão atingidas diretamente por esse empreendimento. Assim, o "pressuposto inconfessado e inconfessável é o próprio aniquilamento das populações que possam representar algum estorvo para a implantação dos grandes projetos governamentais" (MARTINS, op. cit., p. 62).

Os atingidos podem ter a sua situação e o seu modo de vida prejudicados e, em muitos casos, a situação de vida deles pode vir a piorar com a construção das usinas, sendo que essas são implantadas sem que seja levada em consideração a realidade dessas pessoas, as construções ocorrem por imposição e a população às vezes não participa das decisões. Conforme Bermann (2007), a população não participa das tomadas de decisão, pois as informações chegam apenas para ser acatadas, dificultando, portanto o seu envolvimento nas tomadas de decisão. 
Grandes Projetos de Investimento: a Construção de Hidrelétricas e a Criação de Novos Territórios Carla Buiatti Cruz, Vicente de Paulo da Silva

Nesse sentido, buscar compreender o território é imprescindível, uma vez que é nele que a vida cotidiana acontece e onde as ações dos homens acontecem. Além disso, o território é carregado de sentimento, uma vez que os indivíduos criam laços de afetividade e identificações com ele.

\section{O TERRITÓRIO COMO CONSTRUÇÃO COTIDIANA}

O conceito de território é um conceito chave, e seu estudo fundamental para a Geografia. Ao longo do tempo o conceito foi sendo construído por diversos autores que se baseiam em diferentes concepções, expressando sua ideologia.

Assim, diferentes abordagens refletem várias vertentes e pontos de vista, e a posição filosófica que o pesquisador estiver filiado irá determinar a resposta dos referenciais teóricos. Entretanto, "devemos reconhecer que vivenciamos hoje um entrecruzamento de proposições teóricas [...]" (HAESBAERT, 2006, p. 45).

Nesses termos, existem concepções que privilegiam o natural, outras o político e outras o econômico. De acordo com Haesbaert (2006, p. 118) existem duas vertentes interpretativas opostas. A primeira é uma concepção de território naturalista, que concebe o território nos aspectos físicos e materiais, como se o território fosse uma "continuidade do ser". Ainda nessa concepção, existe outra variante dessa interpretação, que valoriza uma "ligação afetiva, emocional, do homem com seu espaço".

A segunda concepção é a que pode ser denominada concepção etnocêntrica do território, concebendo-o assim como uma "construção puramente humana" excluindo-se a relação da sociedade com a natureza, "como se o seu território pudesse prescindir de toda a "base natural"” (HAESBAERT, op. cit, p.119). Entre essas duas concepções existe um ponto em comum, o fato de privilegiar-se mais as dimensões política e cultural do espaço do que a dimensão econômica.
Segundo Sposito (2004), existem também dois caminhos para se compreender o território atualmente. $\mathrm{O}$ primeiro caminho refere-se ao estabelecimento de redes de informações, que devido ao acelerado desenvolvimento tecnológico, propiciam a disseminação de informações cada vez mais rapidamente, tornando-se assim necessário romper distâncias.

Dessa forma, "os territórios perdem as fronteiras, mudam de tamanho dependendo do domínio tecnológico de um grupo ou de uma nação, e mudam, consequentemente, sua configuração geográfica" (SPOSITO, 2004, p. 114). O segundo caminho é o do questionamento do retorno do indivíduo e sua escala do cotidiano "como formas de apreensão das dimensões territoriais e da capacidade de projetar a liberdade como meio de satisfação das necessidades individuais" (SPOSITO, op. cit., p. 115).

Sposito demonstra que uma concepção naturalista do território é amplamente difundida e essa "concepção clássica do imperativo funcional acaba por transformar o território em um elemento da natureza, pelo qual se deve lutar para conquistar ou proteger" (SPOSITO, 2004, p. 113). Dessa forma, o indivíduo cria laços com o seu território, demonstrando apego e sentimentos em relação a este lugar que ele conquista ou protege. indivíduo:

Há também a concepção mais voltada para o

se refere à territorialidade e sua apreensão. Ai tem-se o território do individuo, seu 'espaço' de relações, seu horizonte geográfico, seus limites de deslocamento e de apreensão da realidade. A territorialidade, nesse caso, pertence ao mundo dos sentidos, e portanto da cultura, das interações cuja referencia básica é a pessoa e sua capacidade de se localizar e se deslocar (SPOSITO, 2004, p. 113).

Assim, o território é o lugar onde o indivíduo realiza todas as suas ações e, por isso, cria laços afetivos e de identidade em relação a esse lugar. 
Quando o indivíduo é obrigado a sair desse território, construído e experienciado, há um rompimento desses laços de afetividade. No caso do território na área da Usina Hidrelétrica de Miranda, os moradores foram obrigados a sair de suas terras, sendo difícil seu restabelecimento em outras áreas.

Conforme Haesbaert (2004, p. 85) “o território é um dos principais conceitos que tenta responder à problemática da relação entre a sociedade e seu espaço". Por esse motivo, conforme o autor, quando muito se fala no enfraquecimento dessa relação entre sociedade e espaço mais necessário se faz rediscutir o território e as transformações que nele ocorrem.

Essas transformações ocorrem e são fruto da apropriação do homem e da sua ação, que acaba por determinar e modificar o território. É o que ocorre no caso da Usina Hidrelétrica de Miranda, uma vez que, a partir da ação de alguns indivíduos, houve uma mudança que definiu o futuro não só das ações, mas também da vida dos antigos moradores.

O conceito de território também é importante quando é no território que a vida cotidiana acontece. Por isso, muitos autores escrevem sobre o território do cotidiano, território este onde os eventos do diaa-dia acontecem em forma de hábito. De acordo com Barcellos, território e cotidiano são palavras-chave

pois, ao contrário de noções herdadas do Iluminismo, não tem a pretensão de abarcarem todas as esferas do real [...] elas podem ou não organizar as visões do mundo, visto que permitem perceber a complexidade das relações existentes no campo social permitindo ver as ambiguidades da vida dos homens (BARCELLOS, 1995, p. 41).

Neste sentido, justifica-se a preocupação com estudos que abordem a construção/destruição de territórios, pois não está em jogo apenas um espaço que serve a determinados interesses do poder econômico, mas, acima de tudo, falar de territórios é falar de lugares de experiências de vida, de cotidianidade, de desejos e sonhos, de trocas de experiências, de afeição, de razão de se viver.
Santos (2006, p. 13) diz que o "território é o lugar em que desembocam todas as ações, todas as paixões, todos os poderes, todas as forças, todas as fraquezas, isto é, onde a história do homem plenamente se realiza a partir das manifestações da sua existência". Nesse sentido, para ele, o território é onde o homem desenvolve as suas relações sociais, afetivas, de trabalho, enfim, é o local onde o homem se desenvolve e desenvolve a sua existência. Dessa forma, "o território é o fundamento do trabalho; o lugar da residência, das trocas materiais e espirituais e do exercício da vida" (SANTOS, op. cit, p.14)

Além disso, para ele há uma distinção entre território e território usado, uma vez que não é o território que é uma categoria de análise e sim o território usado, que nada mais é que o "chão mais a identidade", onde a identidade é entendida como o "sentimento de pertencer àquilo que nos pertence" (SANTOS, 2006, p.14). Assim, além dos sentimentos de afeição em relação ao território, os indivíduos também se identificam com eles, criando laços de pertencer a aquele lugar e fazer parte da sua história.

Corrêa (1996, p. 251) aponta que a palavra "território" vem do latim e significa "terra pertencente a alguém". Entretanto, esse "pertencer" não está diretamente relacionado necessariamente a propriedade da terra, e sim a sua apropriação.

Segundo ele, esta apropriação possui dois significados. O primeiro refere-se ao controle do território efetivo; o segundo refere-se à dimensão afetiva que a apropriação pode assumir, sendo associada à identidade de determinados grupos tendo relação com a afetividade espacial. Assim, o "conceito de território vincula-se a uma geografia que privilegia os sentimentos e simbolismos atribuídos aos lugares [...]" (CORRÊA, op. cit, p. 251). Assim, percebese que há uma dimensão simbólica que destaca a afetividade e o apego que os indivíduos depositam no território que eles identificam como sendo o seu território no que se refere ao estudo dessa categoria.

De acordo com Raffestin (1993, p. 143), espaço e território não são termos equivalentes. $\mathrm{O}$ 
Grandes Projetos de Investimento: a Construção de Hidrelétricas e a Criação de Novos Territórios Carla Buiatti Cruz, Vicente de Paulo da Silva

espaço é anterior ao território, sendo que este último se forma a partir do primeiro, por meio da ação de um ator que se apropria do espaço, seja de forma concreta ou de forma abstrata, e o 'territorializa'.

Nessa perspectiva, o território é resultante de um espaço onde foi projetado um trabalho e que, de alguma forma, revela relações de poder. No caso, o estudo da Usina Hidrelétrica de Miranda revela essas relações de poder no espaço, uma vez que prevaleceu o interesse de uns em detrimento de outros, os proprietários, que perderam as suas terras férteis e o seu meio de sobrevivência.

O território é fruto de "uma relação desigual de forças, envolvendo o domínio ou controle político-econômico do espaço e sua apropriação simbólica, ora conjugados e mutuamente reforçados, ora desconectados e contraditoriamente articulados" (HAESBAERT, 2006, p. 121).

Para Neves (1996, p. 271) os territórios "são espaços de ação e de poderes. Os territórios contemporâneos têm diferentes inserções na globalidade que é historicamente fragmentada". Assim, percebe-se que há uma ligação entre território e poder. Mas também é perceptível a idéia de apropriação do território e é esta apropriação que transforma o território, (re)criando-o.

Há autores que dizem que, no bojo da crise contemporânea, estaríamos então vivendo um processo de reterritorialização, ou o que segundo Haesbaert seria a construção de novos territórios. A desterritorialização seria, então, um processo característico da sociedade globalizada.

Nesse sentido, poderíamos dizer que a ocupação da área da Usina Hidrelétrica de Miranda seria essa construção de um novo território, uma vez que teria a atuação de novos atores e a utilização desse território para outras atividades, diferentes das que eram realizadas anteriormente.

No que se refere à desterritorialização, Haesbaert (2004) diz que esse processo refere- se ao abandono do território, enquanto que a reterritorialização refere-se à construção de novos territórios. Dessa forma, estes processos de territorialização, desterritorialização e reterritorialização estão ligados, complementamse incessantemente e, por isso, também estão em unidade. Estes acontecem ao mesmo tempo, para diferentes indivíduos. $\mathrm{Na}$ des-continuidade, reproduz-se elementos/aspectos inerentes à vida diária dos sujeitos sociais, no mesmo ou em diferentes lugares (SAQUET, 2007, p. 163/164).

Assim, os processos de territorialização e desterritorialização se confundem, e os principais elementos que constituem a territorialização também constituem a desterritorialização. Há perda, mas há a reconstrução da identidade, acontecem mudanças nas relações de poder, de vizinhança, de amigos, de novas relações sociais, de elementos culturais, que são reterritorializados; há redes de circulação e comunicação, que substantivam a desterritorialização, o movimento, a mobilidade. (SAQUET, 2007, p. 163, grifo do autor).

De acordo com Ianni (1997, p. 94), a desterritorialização "manifesta-se tanto na esfera da economia como na política e cultura". Assim, para este autor, "desterritorizar significa dissolver ou deslocar o espaço e o tempo", sendo que as noções de espaço e tempo de alteram, e o processo de desterritorialização "tem acentuado e generalizado as condições de solidão. Indivíduos, famílias, grupos, classes e outros segmentos sociais perdem-se no desconcerto do mundo" (IANNI, op. cit, p. 100).

De acordo com Haesbaert (2004), pode haver uma desterritorialização cotidiana, ou a passagem constante de um território a outro sem que para isso o território seja destruído, mas apenas abandonado pelo indivíduo.

No caso da Usina Hidrelétrica de Miranda o território precisou ser abandonado não por vontade dos moradores, mas por imposição, provocando assim uma destruição do território e posteriormente uma reconstrução, com novos usos. 


\section{CONSIDERAÇÕES FINAIS}

Estudar os efeitos, sejam eles ambientais ou sociais, da implantação de um grande projeto de investimento é fundamental para tentar compreender que estes vão além de questões meramente econômicas, mas que causam prejuízos que podem ser irreversíveis. No caso da Usina Hidrelétrica de Miranda, muito além da perda de terras, há também a perda das lembranças, da memória de uma vida que já não existe, modificada pela criação de um lago artificial e a transformação das atividades naquele território.

Esse caso específico, como foi dito na introdução deste trabalho, será objeto de uma nova empreitada com o fim específico de entender os efeitos provocados pela construção da Usina Hidrelétrica de Miranda, no rio Araguari. Isso se deve ao fato de se perceber que essas questões são tratadas de forma muito simplista, como se o pagamento de uma indenização compensasse todas as perdas sofridas pelos proprietários de terras daquele lugar.

Além disso, é importante também destacar que ocorrem transformações no território, acontece desapropriação e a desterritorialização, resultados diretos dos efeitos da construção da usina. Portanto, compreender esses processos é de suma importância para entendermos como os grandes projetos de investimentos interferem na organização do território.

\section{REFERÊNCIAS}

BARCELLOS, J. A. S. Territórios do cotidiano: introdução a uma abordagem teórico contemporânea. In: MESQUITA, Z.; BRANDÃO, C. R. (Org.) Territórios do cotidiano: uma introdução a novos olhares e experiências. Santa Cruz do Sul: EDUNISC, 1995. p. $40-48$.

BERMANN, C. Impasses e controvérsias da hidreletricidade. Disponível em: <http://www. portalpch.com.br/index.php?option $=$ com content $\underline{\text { task }}=$ view\&id $=566 \&$ Itemid $=134>$. Acesso em 02 abr. 2009.
BORTOLETO, E. M. A implantação de grandes hidrelétricas: desenvolvimento, discursos e impactos. Disponível em: $\leq$ http://www.maternatura. org.br/hidreletricas/biblioteca docs/grandes $\% 20$ hidrel\%C3\%A9tricas.pdf $>$. Acesso em 06 abril 2008.

CÔRREA, R. L. Territorialidade e corporação: um exemplo. In: SANTOS, M.; SOUZA, M. A., SILVEIRA, M. L. (Org.). Território. Globalização e Fragmentação. 3. ed. São Paulo: Hucitec, 1996. p. $251-256$.

FEIJÓ, J. A.; OLIVEIRA, E. F. Por que hidrelétricas? Disponível em: $<$ http://www.ilumina. org.br/zpublisher/materias/Estudos Especiais. asp?id=19124>. Acesso em 06 abr. 2008.

HAESBAERT, R. O mito da desterritorialização. Do "fim dos territórios" à multiterritorialidade. Rio de Janeiro: Bertrand Brasil, 2004.

HAESBAERT, R. Territórios Alternativos. 2. ed São Paulo: Contexto, 2006.

Ianni, O. A sociedade global. 5 ed. Rio de Janeiro: Civilização Brasileira, 1997.

MARTINS, J. S. A chegada do Estranho. São Paulo. Hucitec, 1993.

MESQUITA, Z.; BRANDÃO, C. R. (Org.) Territórios do cotidiano: uma introdução a novos olhares e experiências. Santa Cruz do Sul: EDUNISC, 1995.

NEVES, G. R. Territorialidade, desterritorialidade, novas territorialidades (algumas notas). In: SANTOS, M.; SOUZA, M. A. A.; SILVEIRA, M. L. Território, globalização e fragmentação. São Paulo: Hucitec/ ANPUR, 1996. p. 270 - 282.

ONS. Operador Nacional do Sistema Elétrico. Disponível em: <http://www.ons.org.br>. Acesso em: 05 abr. 2009.

RAFFESTIN, C. Por uma geografia do poder. São Paulo: Ática, 1993. 
SANTOS, M. O dinheiro e o território. In: SANTOS et al. Território, territórios. Ensaios sobre o ordenamento territorial. 2. ed. Rio de Janeiro: DP\&A, 2006. p. $13-21$.

SANTOS, M. et al. Território, territórios. Ensaios sobre o ordenamento territorial. 2. ed. Rio de Janeiro: DP\&A, 2006.

SANTOS, M.; SOUZA, M. A., SILVEIRA, M. L. (Org.). Território. Globalização e Fragmentação. 3. ed. São Paulo: Hucitec, 1996.

SAQUET, M. A. Abordagens e concepções de território. São Paulo: Expressão Popular, 2007.

VAINER, C. B.;F.G. ARAÚJO. Grandes projetos hidrelétricos e desenvolvimento regional. Rio de Janeiro: CEDI, 1992.

VAINER, C.B. Conceito de "atingido": Uma revisão do debate. In: ROTHMAN, F. D. (Ed.). Vidas Alagadas. Conflitos Socioambientais Licenciamento e Barragens. Viçosa, MG: Ed. UFV. 2008. p. 39 - 62. 